\title{
A NEW APPROACH OF WEIGHTED GRADIENT FILTER FOR DENOISING OF MEDICAL IMAGES IN THE PRESENCE OF POISSON NOISE
}

\author{
Khan Bahadar Khan, Amir A. Khaliq, Muhammad Shahid, Jawad Ali Shah
}

Original scientific paper We propose a Weighted Gradient Filter for denoising of Poisson noise in medical images. In a predefined window, gradient of the centre pixel is averaged out. Gaussian Weighted filter is used on all calculated gradient values. Proposed method is applied on biomedical images X-Rays and then on different general images of LENA and Peppers. Recovery results show that the proposed weighted gradient filter is efficient and has better visual appearance. Moreover, proposed method is computationally very efficient and faster than Non Local Mean (NLM) filter which is an advanced technique for Poisson noise removal. Proposed method results are also better in terms of performance measures parameters i.e. correlation, Peak Signal-to-Noise Ratio (PSNR), Maximum Structural Similarity Index Measure (MSSIM) and Mean Square Error (MSE) than the conventional Median, Wiener and NLM filter.

Keywords: denoising; image filtering; image processing; medical images; Poisson noise

Primjena ponderiranog stupnjevanog filtra u izoštravanju rendgenskih slika uz postojanje Poissonova šuma

Izvorni znanstveni članak Predlažemo ponderirani stupnjevani filtar za otklanjanje Poissonova šuma na rendgenskim slikama. U unaprijed definiranom prozoru izračunat je gradijent središnjeg piksela. Za izračunavanje vrijednosti gradijenta primijenjen je Gaussov ponderirani filtar. Predložena metoda je primijenjena na biomedicinske rendgenske slike, a zatim na različite uobičajene slike LENE i paprika. Rezultati pokazuju učinkovitost i bolju jasnoću slika uz primjenu ponderiranog stupnjevanog filtra. Uz to, predložena metoda je računalno vrlo učinkovita i brža od Non Local Mean (NLM) filtra koji predstavlja unaprijeđenu metodu za otklanjanje Poissonova šuma. Rezultati predložene metode su također bolji u odnosu na parametre za mjerenje performanse t.j. korelacije, Peak Signal-to-Noise Ratio (PSNR), Maximum Structural Similarity Index Measure (MSSIM) i Mean Square Error (MSE) nego uobičajeni Median, Wiener i NLM filter.

Ključne riječi: filtriranje slike; otklanjanje šuma; Poissonov šum; razvijanje slike; rendgenske slike

\section{Introduction}

In the medical field, digital images play a very significant role in analysis of the anatomy of various organs and are also used in the recognition of various diseases. Unfortunately, different kinds of noises distort medical images due to which image understanding and diagnoses become difficult. Errors during image acquisition process introduce noisy pixel values of image which do not reflect the real scene. Noise contamination in medical images results from different sources, for example, film grains introduce noise if image is acquired from a photograph film. Noise also occurs due to electronic transmission of image data. Transmission medium, measurement, quantization errors and recording medium (film, digital sensor) are some sources that cause noise [1].

Noise reduction is an important pre-processing step in computer vision and medical image processing. Before analysing image data, de-noising is initial step to be taken. Image de-noising removes additive noise and sustains the important signal features [2]. Different noises which may occur in medical images are Gaussian noise, Poisson noise, Speckle noise, Rician noise and Salt and pepper noise etc. MRI images are modelled with Rician Noise while Speckle and Poisson noises are observed in ultrasound and in $\mathrm{x}$-rays respectively [3]. Information about noise model of the image is necessary to choose appropriate denoising algorithm as selection of the denoising algorithm is application dependent.

Noise in an image may be additive or multiplicative in nature [4]. Additive noise can be expressed as

$w(x, y)=s(x, y)+n(x, y)$
Multiplicative noise follows the condition as

$w(x, y)=s(x, y) \cdot n(x, y)$

where $s(x, y)$ represents original signal, $n(x, y)$ shows noisy signal which corrupts the original signal to produce output signal $w(x, y)$ and $(x, y)$ represents the pixel location.

Linear techniques and nonlinear techniques are the basic classification of denoising approaches for Poisson noise mitigation. In linear techniques algorithm is applied on all pixels of image linearly without categorizing pixels into noisy and original value. Disadvantage of Linear technique is that it damages the original pixels because the technique is applied on both noisy and original pixels. Nonlinear denoising consists of two steps, noise detection and noise substitution [5]. Noise location is detected in first step while detected noisy value is replaced by estimated value in second step.

\subsection{Poisson noise}

Poisson noise present is x-ray imaging and nuclear imaging. Receptor surface observes x-ray photons in a random pattern. They cannot be forced to be equally scattered over the receptor surface. Different areas of the receptor surface observed and different number of photons is applied instead of the same average $\mathrm{x}$-rays intensity [3]. Random behaviour of x-ray photons produced image noise in all medical imaging procedures known as quantum noise. Specific quantity of energy is contained in each individual photon. Quantum noise is caused due to quantum structure of an x-ray beam [6]. The number of photons $N$ measured by a given sensor 
element over a time interval $t$ is described by the discrete probability distribution

$$
P(N=k)=\frac{(\lambda t)^{k} \cdot e^{-\lambda t}}{k !}
$$

where $\lambda$ is the expected number of photons per unit time interval. This is a standard Poisson distribution with a rate parameter $\lambda t$ that corresponds to the expected incident photon count. The uncertainty described by this distribution is known as photon noise.

Because the incident photon count follows the Poisson distribution, it has the property that its variance is equal to its expectation, $E[N]=\operatorname{Var}[N]=\lambda t$. This shows that photon noise is signal dependent.

Fig. 1 shows the Power Spectral Density (PSD) of a random signal corrupted by Poisson Noise. The plot clearly shows that the nature of Poisson noise is signal dependent.

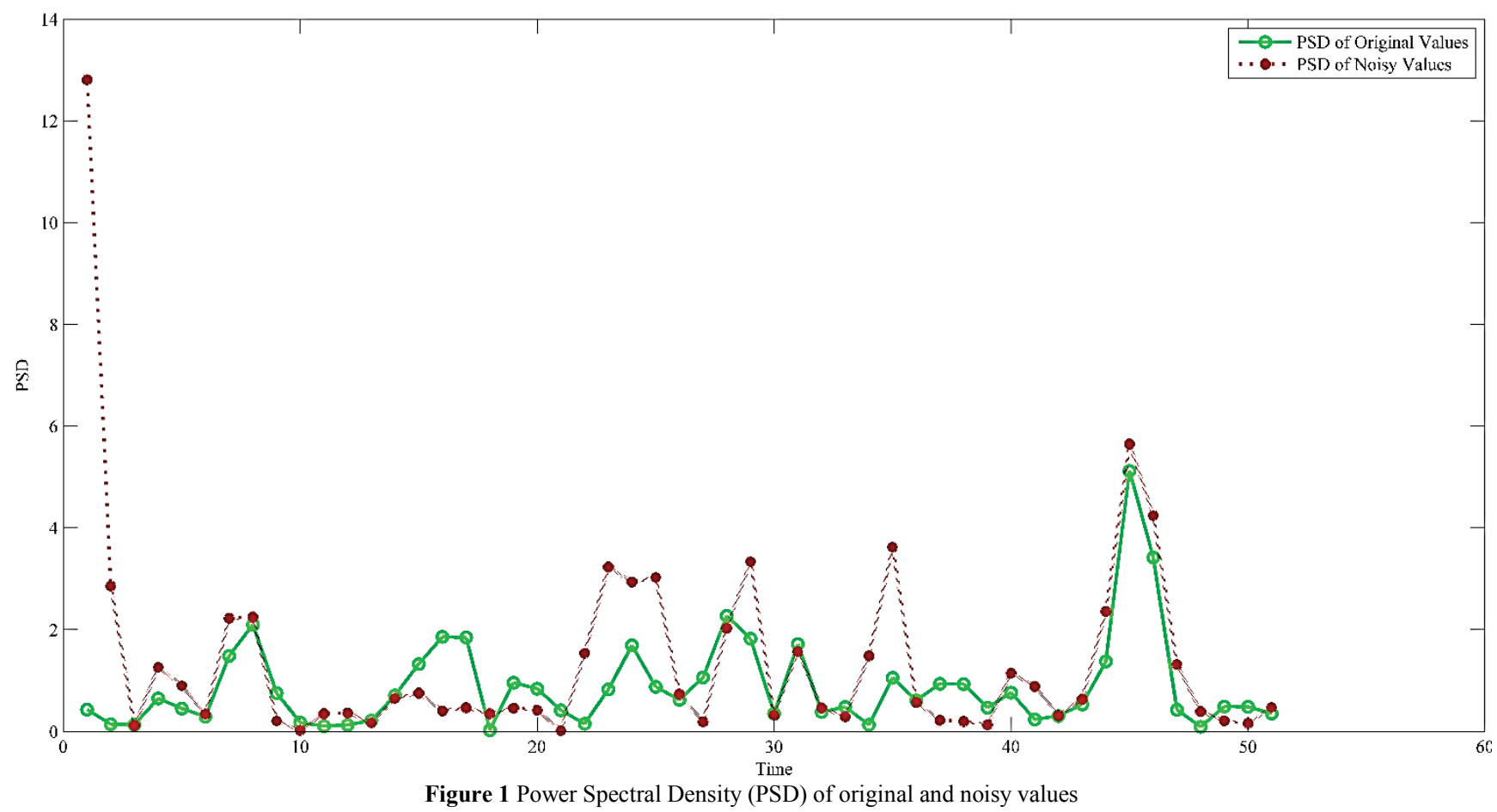

\section{Literature review}

W. H. Richardson and L. Lucy proposed R-L algorithm for denoising of Poisson noise. It consists of multiplicative corrections with iterative minimization of maximum likelihood function. The main limitation of this technique is that the algorithm yields highly noisy estimates after a few iterations, especially when low SNR is observed [7]. Rudin, Osher and Fatemi [8] proposed numerical algorithm based on total variation (TV) using constrained optimization for denoising of images. This technique shows significant performance in the case of edge preserving. Combination of R-L and TV algorithms are used by Dey [9] for denoising of microscopy images modeled with Poisson noise due to photon-limited detection.

A famous technique for Poisson denoising is using a variance stabilizing transform (VST) to transform the noise model from Poisson to Gaussian [10]. Different famous examples for VST are Anscombe's VST [11], and the Haar-Fisz transform [12], which combines Haar wavelet transform with the Fisz transform [13]. When the SNR is very low Anscombe's VST denoising performance is very poor $[11,13]$.

Wavelet based techniques are now mostly used in the denoising of medical images and disease diagnosis. Thresholding is applied in most of these kinds of algorithms while estimation of threshold is the most difficult task [14, 15]. In 2003, Unser used the stress on current developments and highlights progress of wavelet techniques in the areas related to medical imaging [16]. Besbeas [17] compared Bayesian wavelet shrinkage and classical estimators for Poisson counts. Wavelet filters, primary resolution levels, intensity functions, sample sizes, background intensity levels are used for comparison.

Nowak and Kolaczyk [18] described analysis and statistical multiscale modelling for linear inverse problems having Poisson noise. This technique consists of factorization of Poisson likelihood function using statistical multiscale modelling, persuade by portioning of the data space. Willett and Nowak [19] presented a new multiscale technique for image reconstruction, modelled with Poisson noise. This developed technique was computationally fast and practical as compared to other methods e.g. multiscale Haar estimation, platelets and wedgelets. Nowak and Figueiredo [20] presented a novel method for reckoning piecewise homogeneous Poisson process using minimum description length (MDL) criteria.

Luisier [21] proposed a Poisson denoising algorithm PURE-LET based on an unnormalized Haar wavelet transform and the minimization of an unbiased estimate of the MSE for Poisson noise called "Poisson's Unbiased Risk Estimate" (PURE). This signal dependent technique contains a fast interscale thresholding strategy on wavelet 
coefficients. It has been validated that this approach is very competitive in terms of denoising performance and computational complexity.

Buades [22] introduced the Non-local Means algorithm (NLM). NLM is a non-local averaging method, operating on all pixels having similar characteristics. NLM technique is further improved and accelerated by Mahmoudi and Sapiro [23] using pre-selection of neighbourhoods. Pierrick Coupe [24] followed the same idea using parallel processing. Using the same idea, Kostadin Dabov [25] proposed a novel approach for image denoising using non-local adaptive nonparametric filtering. Non Local Mean filter [26, 27] is a modified form of Yaroslavsky filter [28], which averages out the pixels having intensity of similarity locally. The major difference between NLM and Yaroslavsky filter is that similarity between pixels is by using the concept of region comparison rather than the pixel comparison. This approach, which is based on matching and is not limited to local pixels is more effective in noise removal. This technique is particularly useful in de-noising low signalto-noise-ratio (SNR). Shahzad [29] proposed Modified NLM filter consisting of three variants based on the fact that third order moment of the image makes the signal and the noise more prominent thus making it easy to be denoised. Proposed approach is performing more efficiently when compared to conventional filters for non-Gaussian noise.

\section{Proposed technique}

Weighted Gradient filter is helpful in removing Poisson noise from all kinds of images especially medical images as these pass through shot noise \& also increase image quality. Gradient calculation preserves the edges while Gaussian weighted filter performs smoothing of the image.

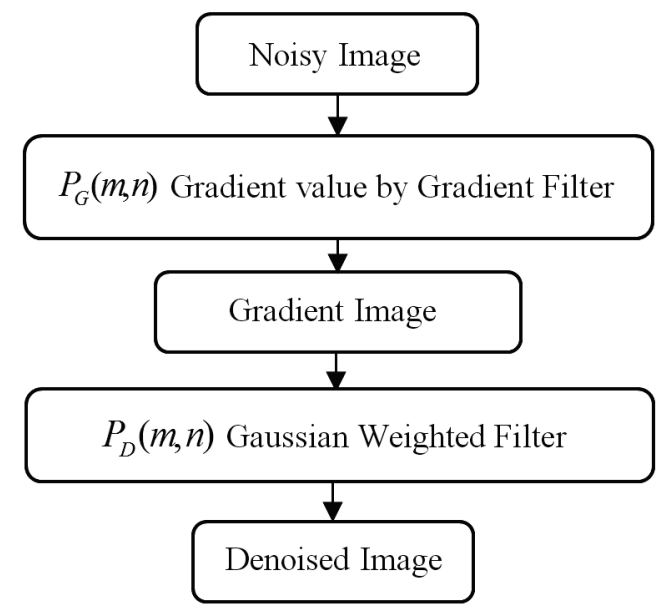

Figure 2 Block diagram of our proposed denoising method

In this method, weighted Gradient filter based denoising of medical images is done to improve the visual quality of image. Poisson noise is added and Gaussian weighted Gradient filter is applied to denoise the image. The Proposed techniques produced better visual results which are helpful in the medical field to detect the symptoms of diseases. Block diagram of proposed method is shown in Fig. 2.
In this proposed method the middle pixel being denoised is considered as the centre of a $3 \times 3$ window. All neighbours from the centre pixel are subtracted and averaged out. Gradients values are filtered through Gaussian weighted filter. Gradient filter preserved the edges of an image and Gaussian weighted filter is used for smoothing. Without Gradient, weighted or any Gaussian filter blur the edges. We slide $3 \times 3$ window pixel by pixel and calculate gradient value for each pixel considered as a centre pixel.

The proposed weighted gradient filter method can be expressed mathematically as:

$$
P_{G}(2,2)=P_{n}(2,2)-\frac{1}{N} \sum_{i=1}^{3} \sum_{j=1}^{3}\left(P_{n}(2,2)-P_{n}(i, j)\right)
$$

$P_{G}(2,2)$ is the middle calculated gradient value of $3 \times 3$ window and $N$ is the total number of neighbour pixels. Gaussian weighted filter is used for smoothing because after gradient calculation we still have some high variations in pixels. Gaussian weighted filter is multiplied element by element with Gradient filter.

$M \times N$ Image is filtered with the Gaussian weighted Gradient filter, and is given by

$P_{D}(m+2, n+2)=\frac{\sum_{i=1}^{p} \sum_{j=1}^{q} w(i, j) P_{G}(m+i, n+j)}{\sum \sum w}$

Complete filtered image is obtained by applying Eq. (5) for $m=0,1,2, \ldots,(M-1)$ and $n=0,1,2, \ldots,(N-1)$. The denominator $w$ is simply the sum of the mask coefficients and, therefore, it is a constant that needs to be computed only once, where $p$ and $q$ are the number of rows and columns.

\section{Simulation and results}

Weighted Gradient filter method is applied on several case-study images of X-Rays, LENA \& Peppers corrupted with Poisson noise. The efficiency of proposed technique using Weighted Gradient filter is shown in Fig. 3a applied on chest x-rays image and results are compared with the results obtained by using Median, Wiener and NLM filter applied directly on noisy images. Denoising results of bones $\mathrm{x}$-rays, LENA and Peppers image are shown in Fig. $3 \mathrm{~b}, 3 \mathrm{c}$ and $3 \mathrm{~d}$ respectively.

Fig. 3 shows (a) Chest X-rays image denoised by median, wiener and NLM filter (b) Bones X-rays image denoised by median, wiener and NLM filter (c) LENA image denoised by median, wiener and NLM filter (d) Peppers image denoised by median, wiener and NLM filter

Proposed weighted gradient filter results are compared with median, wiener and NLM filter in each case. The efficiency of proposed technique is judged both in the case of Median, Wiener and NLM filter alone in terms of visual quality, correlation, MSE, PSNR and Maximum Structural Similarity Index Measure (MSSIM). Proposed technique produced better results in term of 
edge preservation through gradient calculation and smoothening through weighted filter while we face edges loss in the case of median and wiener filters.

Correlation, MSE, PSNR and MSSIM results of proposed technique are shown as coexistent graphical plots with those obtained from Median, Wiener and NLM filters in Fig. 4, Fig. 5, Fig. 6 and Fig. 7 respectively. The SSIM index showing similarity between two images, while considering one image as perfect quality to measure quality of another.
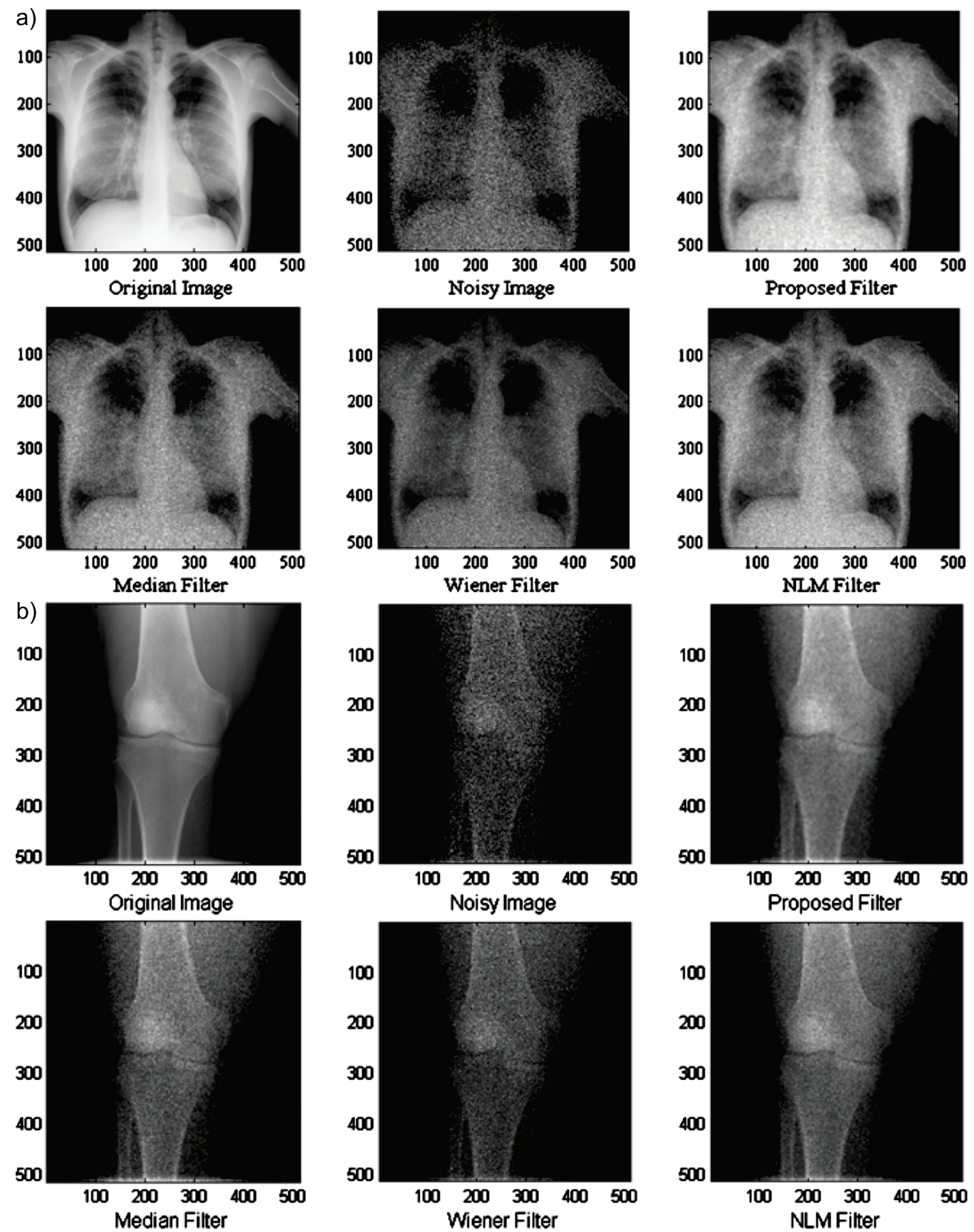

Figure 3(a) Chest X-rays image denoised by median, wiener and NLM filter, (b) Bones X-rays image denoised by median, wiener and NLM filter

Correlation graph of x-rays image de-noised by proposed technique shows significantly higher correlation results than Median, Wiener and NLM filter. The study of the results of MSE, PSNR and MSSIM shows that efficiency of proposed method is significantly better than that of the Median, Wiener and NLM filter.
Overall efficiency of the proposed technique remains significantly better for every level of noise. Visual results show that the x-rays, LENA and Peppers images denoised by proposed technique have a clear and better result than the image de-noised by Median, Wiener and NLM filter. 

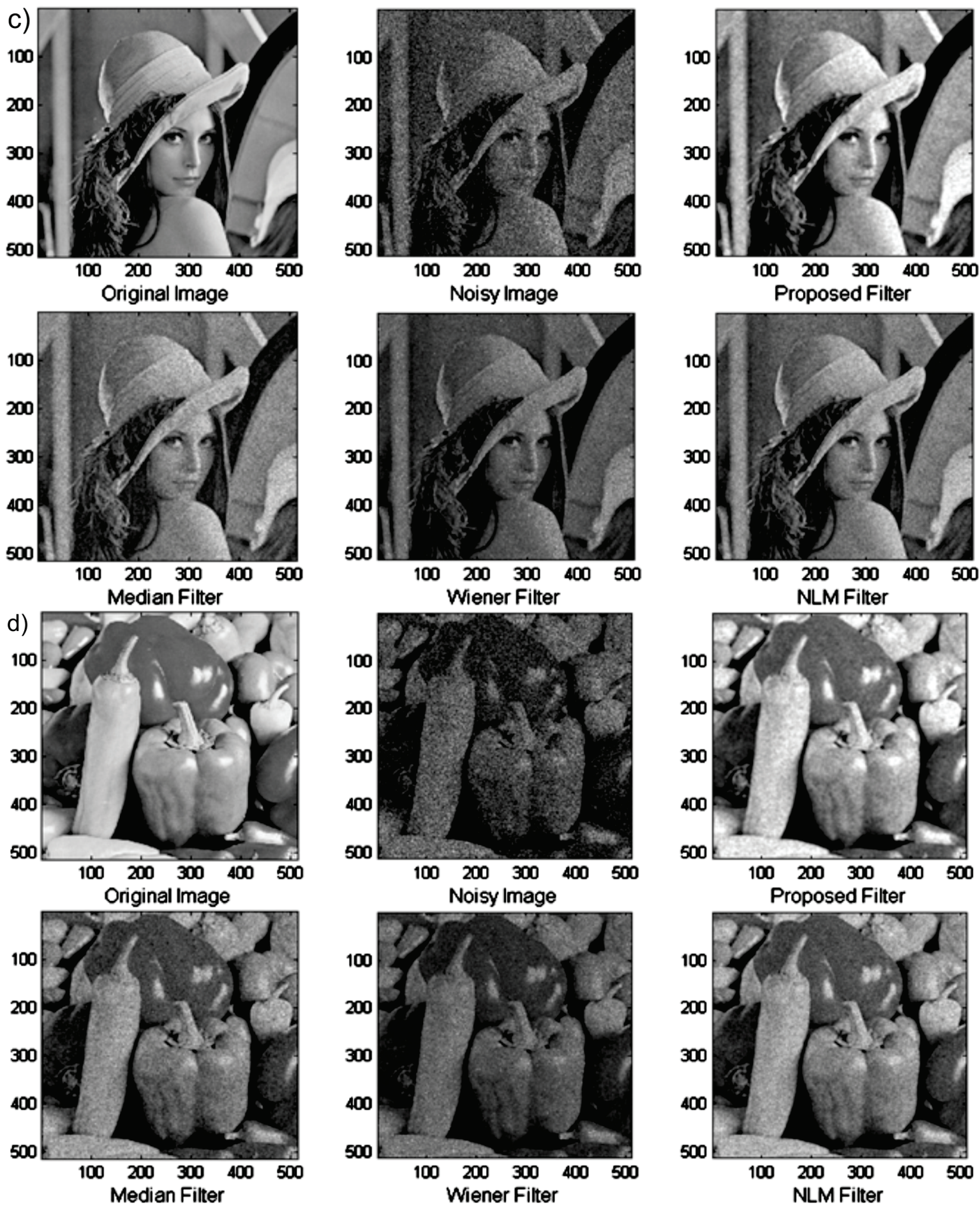

Figure 3(c) LENA image denoised by median, wiener and NLM filter (d) Peppers image denoised by median, wiener and NLM filter

Proposed method is tested on images of LENA, XRays, and Peppers and their correlation and Root Mean Square Error (RMSE) results are compared with median, Wiener and NLM filters which is shown in Tab. 1 where RMSE results are shown in Tab. 2. Tabular results clearly indicate that our proposed technique is more efficient than median, wiener and NLM filters in each case of images.
Our proposed method produced significantly better results and computationally very efficient. Moreover our proposed method is computationally very efficient and faster than NLM filter [29] which is an advanced denoising technique, shown in Tab. 3. MATLAB command is used to calculate computation time.

Table 1 Correlation Comparison Results of LENA, X-Rays, and Peppers Images

\begin{tabular}{|c|c|c|c|c|c|}
\hline Images & Noisy Image & Median Filter & Wiener Filter & NLM Filter & Proposed Technique \\
\hline LENA & 0,6183 & 0,8666 & 0,8506 & 0,8113 & 0,9422 \\
\hline Chest X-Rays & 0,7833 & 0,9448 & 0,9217 & 0,9101 & 0,9819 \\
\hline Bone X-rays & 0,7986 & 0,9428 & 0,9097 & 0,9321 & 0,9796 \\
\hline Peppers & 0,6676 & 0,8937 & 0,8742 & 0,8460 & 0,9551 \\
\hline
\end{tabular}




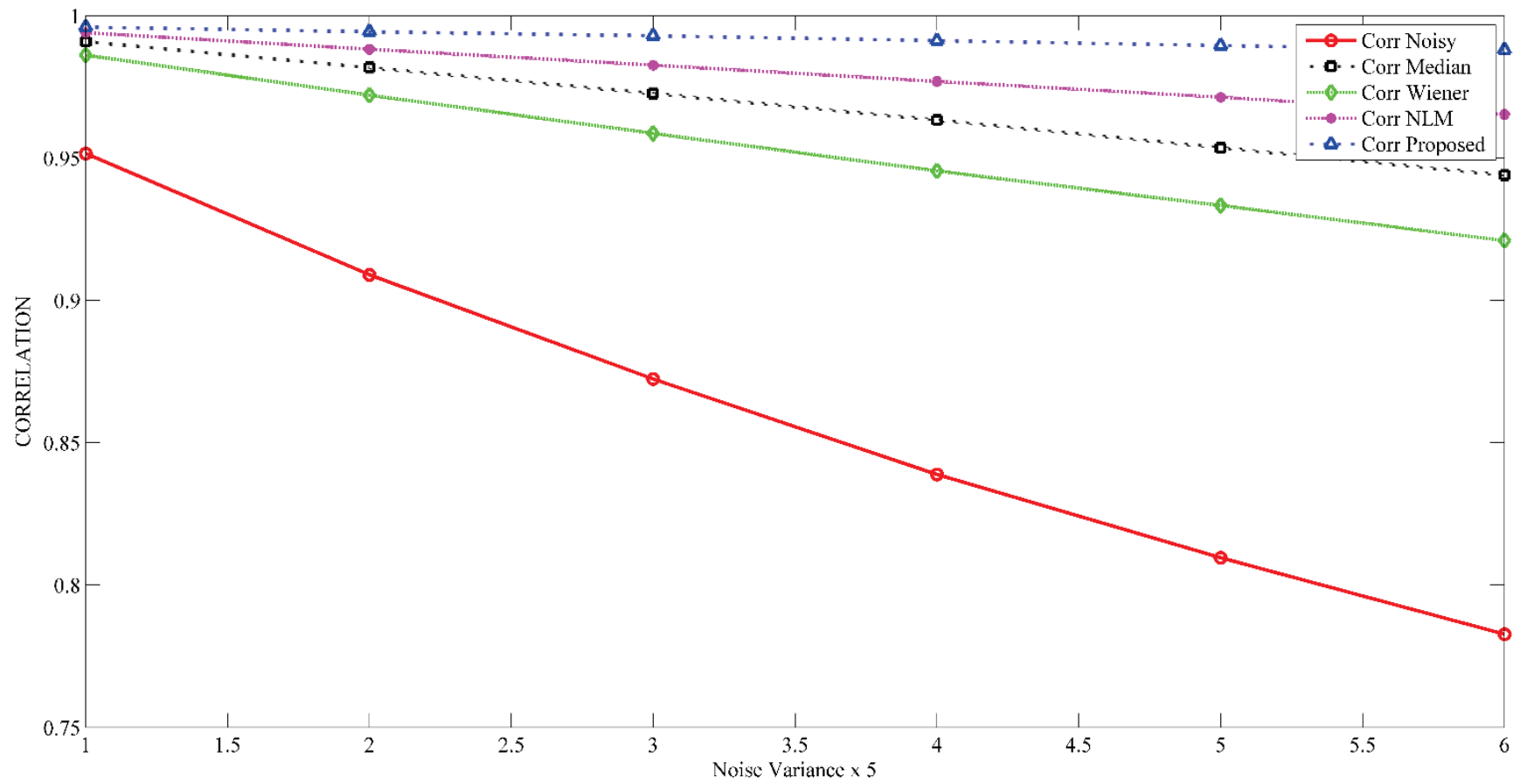

Figure 4 Correlation comparison of Noisy, Median, Wiener and Proposed method

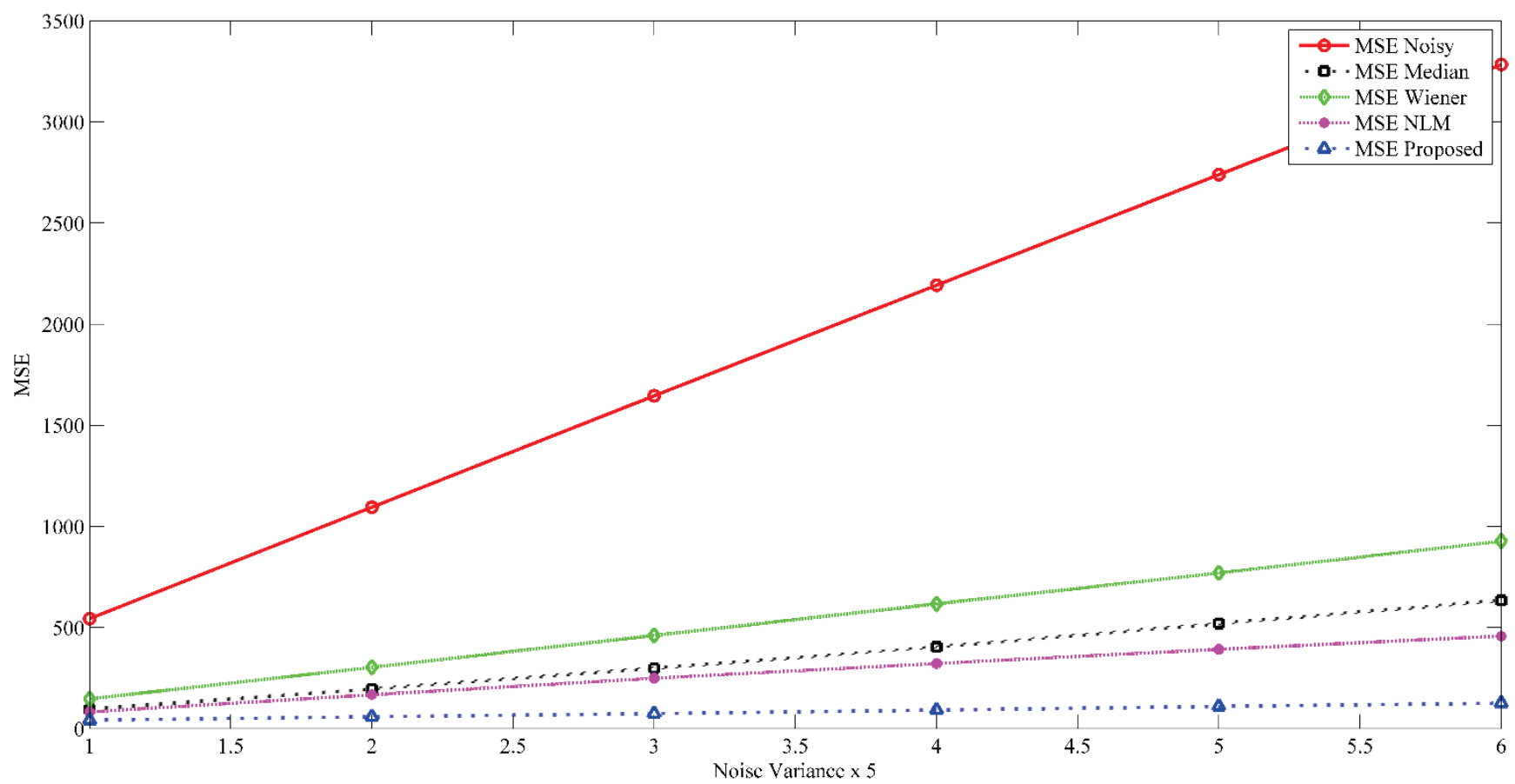

Figure 5 MSE comparison of Noisy, Median, Wiener and Proposed method

Table 2 RMSE of LENA, X-Rays, and Peppers Images

\begin{tabular}{|c|c|c|c|c|c|}
\hline Images & Noisy Image & Median Filter & Wiener Filter & NLM Filter & Proposed Technique \\
\hline LENA & 60,8987 & 27,4451 & 29,0304 & 23,5906 & 16,4309 \\
\hline Chest X-Rays & 57,3418 & 25,0347 & 30,3890 & 20,2344 & 13,8673 \\
\hline Bone X-rays & 16,4991 & 7,1262 & 9,9643 & 7,7840 & 5,7847 \\
\hline Peppers & 60,0287 & 27,1854 & 29,3663 & 22,8532 & 16,1811 \\
\hline
\end{tabular}

Table 3 Elapsed time comparison of proposed technique with Median, Wiener and NLM

\begin{tabular}{|c|c|c|c|c|}
\hline Technique & Median (s) & Weiner (s) & NLM (s) & Proposed (s) \\
\hline Elapsed Time & 0,060589 & 0,022213 & 242,949721 & 1,129565 \\
\hline
\end{tabular}




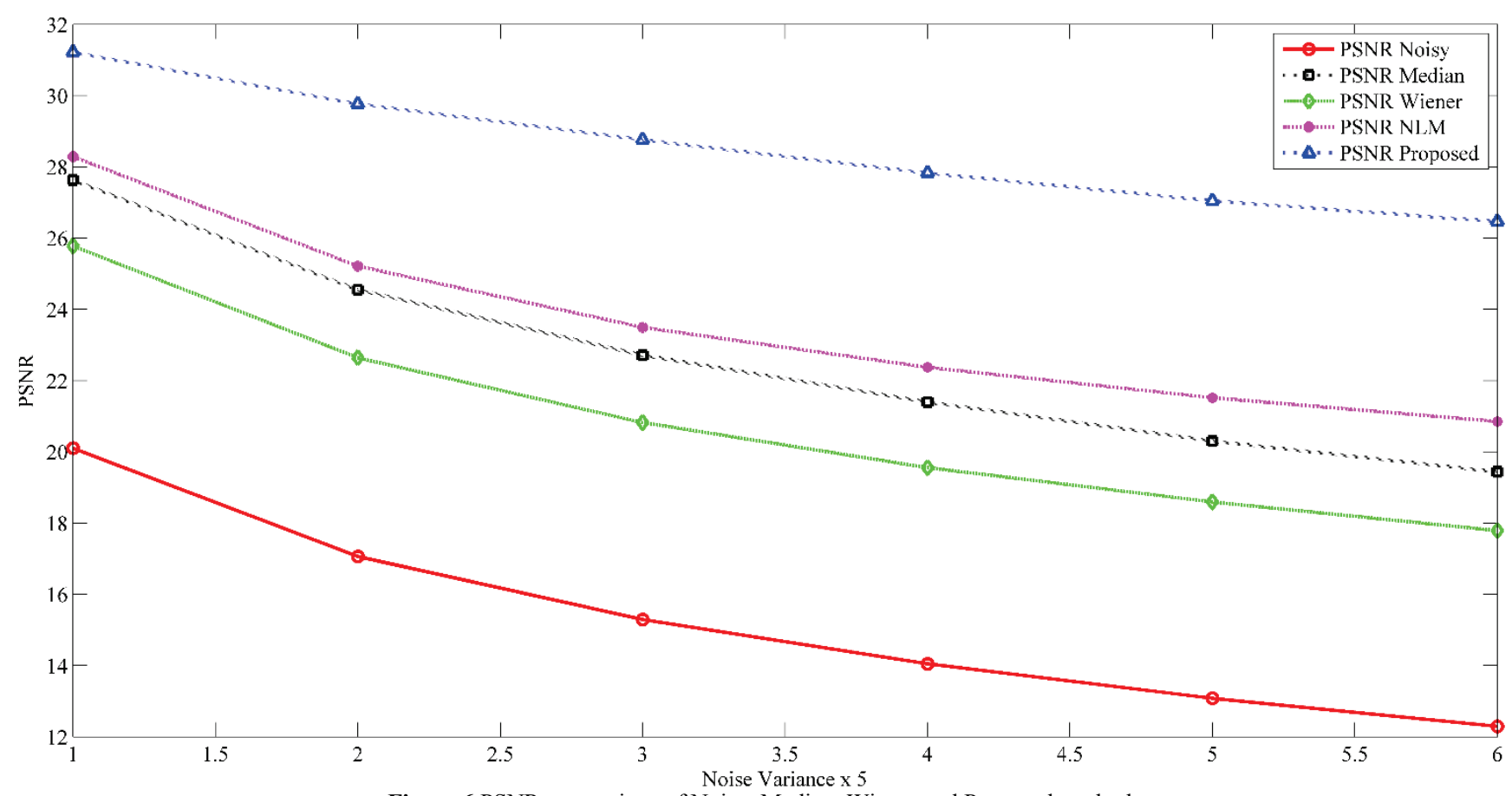

Figure 6 PSNR comparison of Noisy, Median, Wiener and Proposed method

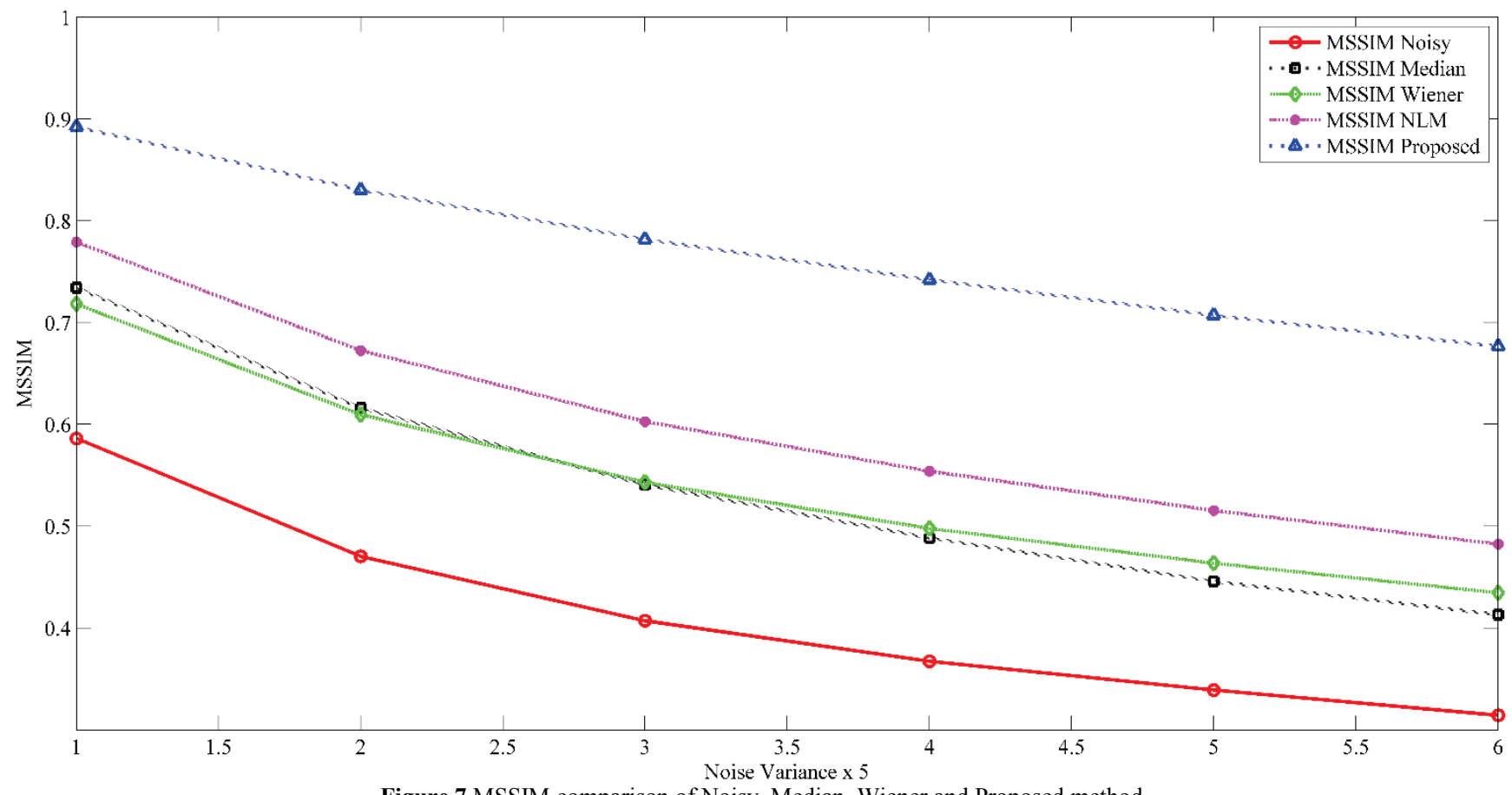

Figure 7 MSSIM comparison of Noisy, Median, Wiener and Proposed method

\section{Conclusion}

Weighted Gradient Filter is proposed for denoising of medical Images modelled with Poisson noise. To illustrate the performance of proposed technique experiments have been conducted on different medical images of X-Rays and general images of LENA \& Peppers. Quantitative performance measures such as correlation, MSE, PSNR and MSSIM are used to check the performance of Poisson noise removing filtering techniques. The experimental results show that the Weighted Gradient Filter performs significantly better than many other conventional filtering techniques like median, wiener and NLM. Proposed techniques produced better results in terms of edge preservation through gradient calculation and smoothening through weighted filter while we face edges loss in the case of median and wiener filters.

\section{References}

[1] Bilcu, R. C.; Vehvilainen, M. A novel decomposition scheme for image denoising. // IEEE International Conference on Acoustics, Speech and Signal Processing, (2007), pp. 577-580

[2] Lakhwinder, K.; Gupta, S.; Chauhan, R. C. Image Denoising Using Wavelet Thresholding. // In ICVGIP. 2, (2002), pp. 16-18

[3] Wang, L.; Lu, J.; Li, Y.; Yahagi, T.; Okamoto, T. Noise Removal for Medical X-Ray Images in Wavelet Domain. // Electrical Engineering in Japan. Vol. 163, Issue 3, 
Translated from Denki Gakkai Ronbunshi. 126-C, 2(2008), pp. 237-244.

[4] Motwani, M. C.; Gadiya, M. C.; Motwani, R. C.; Harris, F. C Jr. Survey of Image Denoising Techniques. // IJCSMC. 3, 6(2014), pp. 234-238.

[5] Koli, Manohar Annappa. "Review of impulse noise reduction techniques. // International Journal on Computer Science and Engineering. 4, 2(2012), p. 184.

[6] Kuan, D. T.; Sawchuk, A. A.; Strand, T. C.; Chavel, P. Adaptive restoration of images with speckle. // IEEE Trans. Acoust. ASSP-35, (1987), pp. 373-383. DOI: 10.1109/TASSP.1987.1165131

[7] Vio, R.; Bardsley, J.; Wamsteker, W. Least-squares methods with Poissonian noise: Analysis and comparison with the Richardson-Lucy algorithm. // Astronomy \& Astrophysics. 436, 2(2005), pp. 741-755. DOI: 10.1051/00046361:20041997

[8] Rudin, L. I.; Osher, S.; Fatemi, E. "Nonlinear total variation based noise removal algorithms. Physica D: Nonlinear Phenomena. 60, 1(1992), pp. 259-268. DOl: 10.1016/01672789(92)90242- $\mathrm{F}$

[9] Nicolas, D.; Blanc-Féraud, L.; Zimmer, C.; Kam, Z.; Olivo-Marin, J.-C.; Zerubia, J. A deconvolution method for confocal microscopy with total variation regularization. // In Biomedical Imaging: Nano to Macro, (2004). IEEE International Symposium on pp. 1223-1226.

[10] Sandeep, P.; Prabhu, K. M. M. Poisson image denoising using fast discrete curvelet transform and wave atom. // Signal Processing. 92, 9(2012), pp. 2002-2017. DOl: 10.1016/j.sigpro.2012.01.008

[11] Anscombe, F. J. The transformation of Poisson, binomial and nega-tive-binomial data. // Biometrika. 35, (1948), pp. 246-254. DOI: 10.1093/biomet/35.3-4.246

[12] Fryzlewicz, P.; Delouille, V.; Nason, G. P. A Haar-Fisz algorithm for Poisson intensity estimation. // Journal of Computational and Graphical Statistics. 13, (2004), pp. 621-638. DOI: 10.1198/106186004X2697

[13] Fisz, M. The limiting distribution of a function of two independent random variables and its statistical application. // Colloquium Mathematicum. 3, (1955), pp. 138-146.

[14] Donoho, D. L.; Jain M. Johnstone. Ideal spatial adaptation by wavelet shrinkage. // Biometrika. 81, 3(1994), pp. 425455. DOI: $10.1093 /$ biomet/81.3.425

[15] Donoho, D. L. De-noising by soft-thresholding. // Information Theory, IEEE Transactions on. 41, 3(1995), pp. 613-627. DOI: 10.1109/18.382009

[16] Unser, M.; Aldroubi, A.; Laine, A. Guest editorial: wavelets in medical imaging. // IEEE Transactions on Medical Imaging. 22, LIB-ARTICLE-2003-004(2003), pp. 285-288.

[17] Besbeas, P.; De Feis, I.; Sapatinas, T. A comparative simulation study of wavelet shrinkage estimators for Poisson counts. // International Statistical Review. 72, 2(2004), pp. 209-237. DOI: 10.1111/j.17515823.2004.tb00234.x

[18] Nowak, R. D.; Kolaczyk, E. D. A statistical multiscale framework for Poisson inverse problems. // Information Theory, IEEE Transactions on. 46, 5(2000), pp. 1811-1825. DOI: $10.1109 / 18.857793$

[19] Willett, R. M.; Nowak, R. D. Fast multiresolution photonlimited image reconstruction. // Biomedical Imaging: Nano to Macro, 2004. IEEE International Symposium on. 2, (2004), pp. 1192-1195.

[20] Nowak, R. D.; Figueiredo, M. A. T. Unsupervised progressive parsing of Poisson fields using minimum description length criteria. // Image Processing, 1999. ICIP 99 Proceedings of International Conference on. 2, (1999), pp. 26-30.
[21] Luisier, F.; Vonesch, C.; Blu, T.; Unser, M. Fast interscale wavelet denoising of Poisson-corrupted images. // Signal Process. 90, 2(2010), pp. 415-427. DOl: 10.1016/j.sigpro.2009.07.009

[22] Buades, A.; Coll, B.; Morel, J. M. A review of image denoising algorithms, with a new one. // SIAM Multiscale Model. Simul. 4, 2(2005), pp. 490-530. DOl: 10.1137/040616024

[23] Mona, M.; Sapiro, G. Fast image and video denoising via nonlocal means of similar neighborhoods. // Signal Processing Letters, IEEE. 12, 12(2005), pp. 839-842. DOI: 10.1109/LSP.2005.859509

[24] Coupé, P.; Yger, P.; Barillot, C. Fast non local means denoising for 3D MR images. // In Medical Image Computing and Computer-Assisted Intervention MICCAI, (2006), pp. 33-40.

[25] Dabov, K.; Foi, A.; Katkovnik, V.; Egiazarian, K. Image denoising by sparse $3 \mathrm{~d}$-transform domain collaborative filtering. // IEEE Trans. on Image Processing. 16, 8(2007), pp. 2080-2095. DOI: 10.1109/TIP.2007.901238

[26] Efros, A.; Leung, T. K. Texture synthesis by nonparametric sampling. // In Computer Vision, 1999. The Proceedings of the Seventh IEEE International Conference on, IEEE. 2, (1999), pp. 1033-1038.

[27] Mohan, M. R.; Sheeba, V. S. A Novel Method of Medical Image Denoising Using Bilateral and NLm Filtering. // In Advances in Computing and Communications (ICACC), 2013 Third International Conference on, IEEE. (2013), pp. 186-191.

[28] Coupé, P.; Hellier, P.; Kervrann, C.; Barillot, C. Nonlocal means-based speckle filtering for ultrasound images. // Image Processing, IEEE Transactions on. 18, 10(2009), pp. 2221-2229. DOI: 10.1109/TIP.2009.2024064

[29] Shahzad, K.; Khaliq, A. A.; Ali Shah, J.; Abdullah, S.; Khan, S. A Hybrid Logarithmic Gradient Algorithm for Poisson Noise Removal in Medical Images. // Advanced Studies in Biology. 6, 4(2014), pp. 181-192.

\section{Authors' addresses}

Khan Bahadar Khan, PhD Scholar

International Islamic University Islamabad Pakistan

FET, IIUI sector $\mathrm{H}-10$, Islamabad, Pakistan

E-mail:kb.khattak@gmail.com, Bahadar.phdee46@iiu.edu.pk

Amir A. Khaliq, Professor/Chairman FET

International Islamic University Islamabad Pakistan

Chairman office, FET, IIUI sector H-10, Islamabad, Pakistan

E-mail: m.amir@iiu.edu.pk

\section{Muhammad Shahid, MS studen}

Muhammad Ali Jinnah University, Islamabad Pakistan

MAJU, Islamabad Expressway, Kahuta Road, Zone-V Islamabad.

Pakistan

E-mail: muhammadshahid313@gmail.com

Jawad Ali Shah, Assistant Professor

International Islamic University Islamabad Pakistan

FET, IIUI sector $\mathrm{H}-10$, Islamabad, Pakistan

E-mail: jawad.shah@iiu.edu.pk 